\title{
Dietary intake of vitamin D during the second half of infancy in Swedish infants
}

\author{
Hans K:son Blomquist', Agneta Frängsmyr', Olle Hernell', \\ Berndt Stenberg ${ }^{2}$ and Ove Bäck ${ }^{3}$
}

Departments of 'Clinical Sciences, Paediatrics, and ${ }^{2}$ Public Health and Clinical Medicine, Dermatology and Venereology, University Hospital, Umeå, Sweden; ${ }^{3}$ Department of Medical Microbiology, Dermatology and Infection, Division of Dermatology and Venereology, Lund University, Lund, Sweden

\section{Abstract}

Background: The physiological requirement for vitamin D in infants and young children is not known. The current Nordic recommendation is a daily intake of $10 \mu \mathrm{g}$ or $400 \mathrm{IU}$. In Sweden a daily supplement with vitamins $\mathrm{A}$ and $\mathrm{D}$ (AD-drops) is recommended from 6 weeks to 6 years of age, but compliance has been questioned, particularly after the first 2 years of life.

Objective: To estimate the total dietary intake of vitamin D and the contribution from AD-drops to the total daily intake during the second half of infancy.

Design: A postal survey on food intake with emphasis on vitamin $\mathrm{D}$, including the recommended AD supplements at 5, 7 and 10 months of age, was answered by parents of 174 infants.

Results: The average total intake of vitamin D was estimated at $11-15 \mu \mathrm{g}$ day ${ }^{-1}$. AD-drops accounted for 76 , 64 and $53 \%$ of the total daily intake of vitamin D at 5, 7 and 10 months of age, respectively. Infant formula, milk cereal drink and commercial infant porridge were the most important food sources of vitamin D in these age groups.

Conclusions: During the second half of infancy, when food is becoming successively more diversified, the average daily vitamin D intake was above the recommended daily intake of $10 \mu \mathrm{g}$ for that age group. Vitamin D supplement accounted for more than half of the daily intake in all age groups studied. Without the recommended supplement the average vitamin D intake would have been below the level considered to lead to a risk of developing rickets in the youngest age group of the healthy, term infants.

Keywords: allergy; infancy; retrospective; questionnaire; vitamin D

Received: 23 Jun. 2004; Revised: 23 Sep. 2004; Accepted: 5 Oct. 2004

\section{Introduction}

Vitamin $\mathrm{D}_{3}$ (cholecalciferol), a steroid-like molecule, is synthesized from 7-dehydrocholesterol in the skin after ultraviolet (UV) light exposure (wavelength $290-315 \mathrm{~nm}$ ). Another source of this vitamin is the diet. Vitamin $\mathrm{D}_{2}$ (ergocalciferol), formed when ergosterol in yeast is irradiated by UV light, is used as a pharmacological preparation of vitamin D. The total requirement of vitamin $\mathrm{D}$ can be met by sun exposure of the skin. Exposure of the face, arms and hands and legs to sunshine for only 6-8 minutes two to three times per week is sufficient to meet the requirement (1). Furthermore, the human body has the capacity to store vitamin $\mathrm{D}$, mainly in the adipose tissue. Children who spend much time outdoors during the summer may acquire adequate vitamin D status during the rest of the year (2).
However, in the Nordic countries with limited sun exposure during the winter season vitamin D deficiency may occur in some risk groups, notably infants, if the diet does not provide a sufficient amount of vitamin D.

Infants and children need vitamin D for resorption and deposition of calcium and phosphate in bones and teeth. However, vitamin D is also a prohormone, converted to the active hormone 1,25dihydroxyvitamin $\mathrm{D}_{3}$ by metabolic steps in the liver and kidney. The hormone has several metabolic effects, e.g. development and function of various cells and tissues, including the immune system (3). Our knowledge of the exact requirements of vitamin $\mathrm{D}$ in various age groups is incomplete.

The synthesis of vitamin $\mathrm{D}$ in the skin after sun exposure and dietary intake was considered 
insufficient in Swedish infants. Therefore, a preventive strategy was launched in 1978. Since then, the National Board of Health and Welfare has recommended daily supplements of vitamins A (1000 retinol equivalents) and $\mathrm{D}(10 \mu \mathrm{g}$ vitamin $D_{3}$ ) for all infants from 6 weeks to 6 years of age (4). A study in 1996 revealed that compliance was incomplete, particularly after the first 2 years, without obvious clinical manifestations of rickets (5). Furthermore, in 1999 the Swedish Pediatric Committee on Nutrition of the Swedish Pediatric Association and the National Food Administration suggested that the supplement of vitamin A should be discontinued and the supplement of vitamin D limited to the first 2 years of life (6). However, the National Board of Health and Welfare decided to stick to the previous recommendation for the time being. Vitamin AD supplementation has also been discussed in other Nordic countries (7-10) and new Nordic recommendations are under way (11).

There is an ongoing discussion on the intake of vitamin D required not only to prevent deficiency but also to ascertain optimal bone development (12, 13). Recent findings also suggest that vitamin $D$ may have immune-modulating effects in suppressing autoimmune responses in various experimental animal models (3). Therefore, a possible role of vitamin $\mathrm{D}$ in the regulation of Th1- and Th2mediated immune responses may have implications for the development of allergy and autoimmune diseases during early childhood. Infant formulae, milk cereal drinks, porridges and some other complementary feeding products on the Swedish market are supplemented with vitamin $D_{3}$ in accordance with European Union (EU) regulations. Therefore, it was hypothesized that too high vitamin $\mathrm{D}$ intake during infancy may partly explain why the prevalence of atopic diseases among Swedish children has increased considerably during the past few decades (14). The aim of the present investigation was to estimate the total intake of dietary vitamin D in infants up to 10 months of age, with special reference to the contributions from food and vitamin D supplements in relation to the recommended daily intake for that age group.

\section{Material and methods}

\section{Subjects}

Parents of all 206 infants born consecutively at Umeå University Hospital during a 3 month period from January to April 1997 were asked retrospectively to fill in a postal questionnaire 1 year later. The questionnaire gave structured answers concerning the food intake of the infants at 5, 7 and 10 months of age, including vitamin supplements. The surveys were numbered and one reminder was sent if necessary. After return of the questionnaires they were coded and analysed, unidentified. The average intake of vitamin D from regular diet and supplementary sources was calculated for the three age groups. The study was approved by the ethics committee of the Faculty of Medicine and Odontology, Umeå University.

\section{Vitamin $D$ and food intake}

Breast milk was assumed to contain a mean of $0.02 \mu \mathrm{g}$ vitamin $\mathrm{D}_{3} 100 \mathrm{ml}^{-1}$ (15). The volume of breast milk per nursing episode was estimated at $134 \mathrm{~g}$ for children below 8 months of age and $102 \mathrm{~g}$ thereafter (16). The amount of milk given as comfort or consolation was estimated at $25 \mathrm{~g}$. The feeding frequency was supposed to be seven times per day when breast-feeding was the only source of nutrition (17). Infant formulae on the Swedish market contain $1.3 \mu \mathrm{g}$ vitamin $\mathrm{D}_{3} 100 \mathrm{ml}^{-1}$ and different milk cereal drinks contain 1.1-1.4 $\mu \mathrm{g}$ $100 \mathrm{ml}^{-1}(18,19)$. Standard milk and yoghurt ( $3 \%$ fat) contain $0.02 \mu \mathrm{g}$ vitamin D $100 \mathrm{ml}^{-1}$, while the corresponding lower fat products are fortified and contain $0.38 \mu \mathrm{g}$ vitamin D $100 \mathrm{ml}^{-1}$. Industrymanufactured porridge contains $2.6 \mu \mathrm{g}$ vitamin $\mathrm{D}_{3}$ $130 \mathrm{~g}^{-1}$ (18, 19). Home-cooked porridge was considered the same as oatmeal porridge without vitamin D supplementation.

Manufactured complementary food contains between 0.20 and $0.24 \mu \mathrm{g}$ vitamin D $100 \mathrm{~g}^{-1}$, and in the present calculations $0.24 \mu \mathrm{g}$ was used as a proxy. Fruit desserts contain $0.08 \mu \mathrm{g}$ vitamin D $100 \mathrm{~g}^{-1}$. The figures are based on the raw products, not on analysis of manufactured products (personal information from Nestlé, Sweden, and Semper, Sweden). The intake of meat and fish from home-cooked meals was estimated at 15.9 and $24 \mathrm{~g}$ per serving at 7 months and 24.3 and $27.5 \mathrm{~g}$ per serving at 10 months of age, respectively (Lind $\mathrm{T}$, unpublished observations). The content of vitamin D in food was calculated from figures given by the National Food Administration (15). The content of vitamin D in fish varies considerably depending on species, percentage of fat and season. Therefore, the content of vitamin D was approximated to $2 \mu \mathrm{g} 100 \mathrm{~g}^{-1}$ as 
an average for the common local supply of fish. Supplementary AD-drops contain 400 IU vitamin $\mathrm{D}_{3}$ per dose, corresponding to $10 \mu \mathrm{g}_{\text {day }}{ }^{-1}$, with no difference between water- and oil-soluble formulations. A very small number of children also received other vitamin formulations occasionally, but the contribution was considered marginal and excluded from the calculations.

\section{Results}

The questionnaires were returned by 174 families, i.e. $85 \%$ of those invited. The total intake of vitamin $\mathrm{D}$ is shown in Table 1. The contribution of vitamin $\mathrm{D}$ from various food items is further specified in Table 2. Cow's milk and dairy products were given to 33,77 and $91 \%$ of the children aged 5, 7 and 10 months, respectively. Most children were given standard milk with 3\% fat, while 20-25\% received low-fat milk with $1.5 \%$ fat and fortified with vitamin $\mathrm{D}_{3}$.

At 7 months $25 \%$ and at 10 months $75 \%$ of the infants were given home-cooked meat or fish. In addition, 70 and $75 \%$, respectively, were served a daily meal of complementary baby food and a dessert with preserved fruit or jam. The broadest range of vitamin $\mathrm{D}$ intake was seen in the older age groups, with the highest intakes in children given industry-produced vitamin D-fortified food, and the lowest in children consuming home-cooked meals.

At 5, 7 and 10 months of age, 80, 76 and $74 \%$ of the children, respectively, were given the recommended vitamin $\mathrm{D}_{3}$ supplement of $10 \mu \mathrm{g}_{\text {day }}{ }^{-1}$, while $4 \%$ (seven infants) never received any ADdrops and the rest received the supplement intermittently. In $90 \%$ of the infants the AD-drops were an oil-soluble formulation. The daily intake of

Table I. Daily intake of vitamin D $(\mu \mathrm{g})$ from food and AD-drops in 5-, 7- and I0-month-old infants $(n=174)$

\begin{tabular}{lccc}
\hline & \multicolumn{3}{c}{ Age (months) } \\
\cline { 2 - 4 } & $\mathbf{5}$ & $\mathbf{7}$ & 10 \\
\hline Total food $^{\mathrm{a}}$ & $2.6 \pm 4.4$ & $4.7 \pm 4.5$ & $6.9 \pm 3.7$ \\
AD-drops $^{\mathrm{a}}$ & $8.4 \pm 3.2$ & $8.2 \pm 3.3$ & $7.9 \pm 3.6$ \\
\% of total intake & 76 & 64 & 53 \\
Total intake & $11.0 \pm 5.5$ & $12.9 \pm 5.6$ & $14.8 \pm 4.8$ \\
Range & $0.2-29.0$ & $0.4-32.2$ & $1.1-31.0$ \\
QI & 10.2 & 10.2 & 12 \\
Q3 & 12.2 & 16.2 & 18 \\
\hline
\end{tabular}

${ }^{\mathrm{a}}$ Mean $\pm \mathrm{SD}$

Q: quartile.
Table 2. Dietary intake of vitamin D ( $\mu \mathrm{g})$ from specified food items in 5-, 7- and 10-month-old infants $(n=174)$

\begin{tabular}{|c|c|c|c|}
\hline & \multicolumn{3}{|c|}{ Age (months) } \\
\hline & 5 & 7 & 10 \\
\hline Breast milk & $0.2 \pm 0.1(8)$ & $0.15 \pm 0.1$ & $0.025 \pm 0.04$ \\
\hline Infant formula & $2.0 \pm 4.1(77)$ & $0.5 \pm 2.1(\mathrm{II})$ & $0.1 \pm I . I(2)$ \\
\hline Porridge, manufactured & $0.4 \pm 0.8(15)$ & $0.7 \pm 0.8(15)$ & $0.7 \pm 0.9(10)$ \\
\hline Cow's milk & $0.03 \pm 0.1(1)$ & $0.1 \pm 0.3(2)$ & $0.1 \pm 0.2(2)$ \\
\hline Milk cereal drink & & $2.6 \pm 3.4(55)$ & $4.5 \pm 3.4(66)$ \\
\hline Canned baby food & & $0.1 \pm 0.2(I)$ & $0.2 \pm 0.4(3)$ \\
\hline Dessert & & $0.1 \pm 0.1$ & $0.1 \pm 0.1(1)$ \\
\hline Meat, home-cooked & & 0 & $0.2 \pm 0.2(2)$ \\
\hline Fish, home-cooked & & $0.2 \pm 0.5(5)$ & $0.8 \pm 0.6(11)$ \\
\hline Egg & & $0.2 \pm 0.5(5)$ & $0.2 \pm 0.5$ \\
\hline Total food & $2.6 \pm 4.4(100)$ & $4.7 \pm 4.5(100)$ & $6.9 \pm 3.7(100)$ \\
\hline
\end{tabular}

Data are shown as mean $\pm S D$ (\% of total food).

vitamin $\mathrm{D}$ in children not given $\mathrm{AD}$-drops is shown in Table 3.

\section{Discussion}

A daily intake of $5 \mu \mathrm{g}$ vitamin $\mathrm{D}$ is considered to prevent the development of rickets $(12,13)$. To ascertain maximal absorption of calcium and normal bone development, the new Nordic recommendation is a daily supplement of $10 \mu \mathrm{g}$ vitamin $\mathrm{D}_{3}$ from 2-4 weeks to 2 years of age (11). The present study found that the average intake of vitamin $\mathrm{D}_{3}$ was approximately $12 \mu \mathrm{g}$ day $^{-1}$. This intake is above the risk level for developing rickets and above the new Nordic recommendation, but below the $25 \mu \mathrm{g}$ day $^{-1}$ considered to be the tolerable upper intake level (13).

Breast milk, commercial infant formula, milk cereal drink and manufactured porridge contributed approximately half the vitamin D intake in the older age groups and AD-drops the remaining half. In the 5-month-olds, AD-drops contributed $76 \%$ of

Table 3. Daily intake of vitamin $D(\mu g)$ in seven infants without AD-drops

\begin{tabular}{lccc}
\hline Infant no. & \multicolumn{3}{c}{ Age (months) } \\
\cline { 2 - 4 } & $\mathbf{5}$ & $\mathbf{7}$ & 10 \\
\hline 1 & 11 & 10 & 7 \\
2 & 0.2 & 5.4 & 12 \\
3 & 0.2 & 0.4 & 1.1 \\
4 & 0.2 & 1.2 & 9.1 \\
5 & 1.4 & 8.2 & 9.0 \\
6 & 0.2 & 2.0 & 9.0 \\
7 & 1.3 & 6.2 & 7.0 \\
\hline
\end{tabular}


the total intake. It should be noted that any contribution by endogenous synthesis of vitamin $\mathrm{D}_{3}$ in the skin has not been considered in the present study. For most infants this contribution is not trivial, although Umeå is situated at a latitude of $63.5^{\circ} \mathrm{N}$. The physical health of the infants was checked during regular visits to the well-baby clinics. To the authors' knowledge none of them has developed symptoms of hypovitaminosis D or rickets. The children were born at the beginning of the year and were 5-7 months old in the summer, when their mothers were exposed to sunshine and then produced breast milk with higher levels of vitamin D (13). Sun exposure of mother and child may be one explanation for the absence of signs of clinical rickets in infants without intake of ADdrops.

The number of infants in this study was relatively low. Families from both rural and urban areas and families with different educational backgrounds were included. The response rate to the questionnaire was considered satisfactory, with regard to both the entire questionnaire and the particular detailed queries. Focusing on vitamin D, the dropouts appeared to be random. The results are likely to be representative of the county of Västerbotten and probably of the whole of Sweden at the time of the study. The ages of 5, 7 and 10 months were chosen to estimate the intake of vitamin D during weaning, when the diet is becoming diversified and the vitamin $\mathrm{D}$ intake may begin to vary between infants. The study may suffer from recall bias, since questions regarding the diet and the vitamin supplements were answered retrospectively 3-9 months after the actual intake. The only vitamin D sources of importance in the diet of the investigated age groups were infant formulae, milk cereal drinks, porridges, vitamin-fortified (low-fat) cow's milk and yoghurt, fortified margarine and fat fish. Any table spread used during cooking or as dressing on porridge was not included in the analyses.

Recent data on the actions of vitamin D metabolites also demonstrate profound effects on the immune system in experimental animals, and a vitamin D-driven Th1/Th2 shift has been postulated (20). During gestation the immune system of the human foetus displays a Th2 profile to prevent rejection of maternal tissues. After delivery, with hormonal readjustment and encountering a new microbial environment, the immune system of the newborn restores a proper Th1/Th2 balance (21). If it does not, there may be a risk of a sustained Th2-type response, characterized by interleukin-4mediated immunoglobulin $\mathrm{E}$ production and manifestations of allergic diseases such as atopic dermatitis, allergic rhinitis and asthma. Recent animal data suggest that 1,25-dihydroxyvitamin $\mathrm{D}_{3}$ may amplify Th2-mediated immune responses (22). This would imply the possibility that the present high level of vitamin D intake in some of the newborns may counteract a restoration of a normal immune response and thus favour the development of an allergic phenotype. Dietary vitamin $\mathrm{D}$, metabolized to the active hormone, could be one of several environmental factors (23) contributing to the increase of allergic diseases during the past few decades. A pending question is: how narrow is the physiological window for different metabolic effects of various doses of vitamin D?

\section{Acknowledgements}

We are grateful for financial support from the Edvard Welander and Finsen Foundations, The Vårdal Foundation and Förstamajblommans Riksförbund.

\section{References}

1. Holick MF. Sunlight and vitamin D. Both good for cardiovascular health. J Gen Intern Med 2002; 17: 733 5.

2. Poskitt EME, Cole TJ, Lawson DEM. Diet, sunlight and 25-hydroxyvitamin D in healthy children and adults. BMJ 1979; i: 221-3.

3. DeLuca HF, Cantorna MT. Vitamin D: its role and uses in immunology. FASEB J 2001; 15: 2579-85.

4. National Board of Health and Welfare. Kungörelse om AD-vitaminprofylax hos barn. SOSFS(M) 1978:25. (In Swedish.)

5. Modin K, Sandström H, Blomquist HK, Nilsson M. Ingen klinisk rakit trots inkomplett AD-tillägg. Läkartidningen 1998;8:745-8. (In Swedish.)

6. Axelsson I, Gebre-Medhin M, Hernell O, Jakobsson I, Fleischer Michaelsen K, Samuelson G. AD-dropparna kan ersättas med D-droppar. Läkartidningen 1999;18:2200-4. (In Swedish.)

7. Marjamäki L, Räsänen $\mathrm{M}$, Uutisalo L, Ahonen S, Veijola R, Knip M, Virtanen SM. Use of vitamin D and other dietary supplements by Finnish children age of 2 and 3 years. Int J Vitam Nutr Res 2004; 74: 27-34.

8. Mølgaard C, Michaelsen KF. Vitamin D and bone health in early life. Proc Nutr Soc 2003; 62: 823-8. 
9. Brunvand L, Lindemann R. Rickets in children in Norway - an epidemic of concern for Norwegian authorities? Tidskr Nor Laegeforen 1999; 119: 1328-9. (In Norwegian.)

10. Olafsdottir AS, Wagner KH, Thorsdottir I, Elmadfa I. Fat-soluble vitamins in the maternal diet, influence of cod liver oil supplementation and impact of the maternal diet on human milk composition. Ann Nutr Metab 2001; 45: 265-72.

11. Nordic Nutrition Recommendations. 4th edn. Nordic Council of Ministers, Nord Report 2004; 4: 013.

12. American Academy of Pediatrics. Prevention of rickets and vitamin D deficiency: new guidelines for vitamin D intake. Pediatrics 2003; 111: 908-10.

13. Report of the Scientific Committee on Food on the revision of essential requirements of infant formulae and follow-on formulae. European Commission, Scientific Committee on Food; Brussels, Belgium, 18 May 2003. pp. 101 -4. (http://europa.eu.int/comm/foods/fs/sc/scf/index-en.html).

14. Åberg N, Hesselmar B, Åberg B, Eriksson B. Increase of asthma, allergic rhinitis and eczema in Swedish schoolchildren between 1979 and 1991. Clin Exp Allergy 1995; 25: $791-4$.

15. National Food Administration. Livsmedelstabell. Energi och näringsämnen. Uppsala: Livsmedelsverkets förlag; 1996. (In Swedish.)

16. Paul AA, Black AE, Evans J, Cole TJ, Whitehead RG. Breastmilk intake and growth in infants from two to ten months. J Hum Nutr Dietet 1988; 1: 437-50.

17. Hörnell A, Aarts C, Kylberg E, Hofvander Y, GebreMedhin M. Breastfeeding patterns in exclusively breastfed infants: a longitudinal prospective study in Uppsala, Sweden. Acta Paediatr 1999; 88: 203-11.

18. Fakta om Findus grötar. Findus barnmatsinformation. Bjuv: Svenska Nestlé; 1999. (In Swedish.)

19. En faktabok om Sempers barnmat och specialkoster. Stockholm: Semper konsumentkontakt; 1998. (In Swedish.)

20. Overbergh L, Decallonne B, Waer M, Rutgeerts O, Valckx D, Casteels KM, et al. 1- $\alpha, 25$-Dihydroxyvitamin D3 induces an autoantigen-specific T-helper 1/T-helper 2 immune shift in NOD mice immunized with GAD65 (p524-543). Diabetes 2000; 49: 1301-7.

21. Prescott SL, Macaubas C, Smallacombe TB, Holt BJ, Sly PD, Holt PG. Development of allergen-specific Tcell memory in atopic and normal children. Lancet 1999; 353: 196-200.

22. Matheu V, Bäck O, Mondoc E, Issazadeh-Navikas S. Dual effects of vitamin D-induced alteration of Th1/Th2 cytokine expression: enhancing IgE production and decreasing airway eosinophilia in murine allergic airway disease. J Allergy Clin Immunol 2003; 112: 585-92.

23. Wjst M, Dold S. Genes, factor X, and allergens: what causes allergic diseases? Allergy 1999; 54: 757-9.

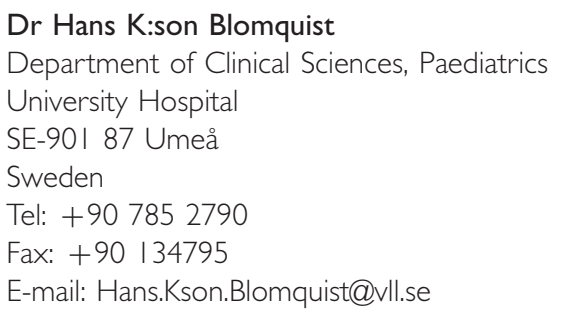

